\title{
pH Sensitive Microcapsules for Delivery of Corrosion Inhibitors
}

\author{
Wenyan Li and Luz M. Calle \\ NASA Corrosion Technology Laboratory \\ Kennedy Space Center, FL 32899
}

A considerable number of corrosion problems can be solved by coatings. However, even the best protective coatings can fail by allowing the slow diffusion of oxygen and moisture to the metal surface. Corrosion accelerates when a coating delaminates. Often, the problems start when microscopic nicks or pits on the surface develop during manufacturing or through wear and tear. This problem can be solved by the incorporation of a self-healing function into the coating. Several new concepts are currently under development to incorporate this function into a coating. Conductive polymers, nanoparticles, and microcapsules are used to release corrosion-inhibiting ions at a defect site.

The objective of this investigation is to develop a smart coating for the early detection and inhibition of corrosion. The dual function of this new smart coating system is performed by $\mathrm{pH}-$ triggered release microcapsules. The microcapsules can be used to deliver healing agents to terminate the corrosion process at its early stage or as corrosion indicators by releasing dyes at the localized corrosion sites. The dyes can be color dyes or fluorescent dyes, with or without $\mathrm{pH}$ sensitivity.

Microcapsules were formed through the interfacial polymerization process. The average size of the microcapsules can be adjusted from 1 to 100 micron by adjusting the emulsion formula and the microcapsule forming conditions. A typical microcapsule size is around 10 microns with a narrow size distribution. The $\mathrm{pH}$ sensitivity of the microcapsule can also be controlled by adjusting the emulsion formula and the polymerization reaction time.

Both corrosion indicator ( $\mathrm{pH}$ indicator) and corrosion inhibitor containing microcapsules were formed and incorporated into paint systems. Test panels of selected steels and aluminum alloys were painted using these paints. Testing of compatibility between the microcapsule system and different paint systems are in progress.

Initial experiments with the microcapsule containing paint show visible color changes at induced corrosion sites and improvement of corrosion protection. Further investigation of the performance of the coating using electrochemical techniques and long term exposure are currently underway. 


\title{
pH Sensitive Microcapsules for Delivery of Corrosion Inhibitors
}

\author{
Wenyan Li \\ Luz M. Calle
}

Corrosion Technology Laboratory

NASA Kennedy Space Center 


\section{Space Shuttle and Corrosion}

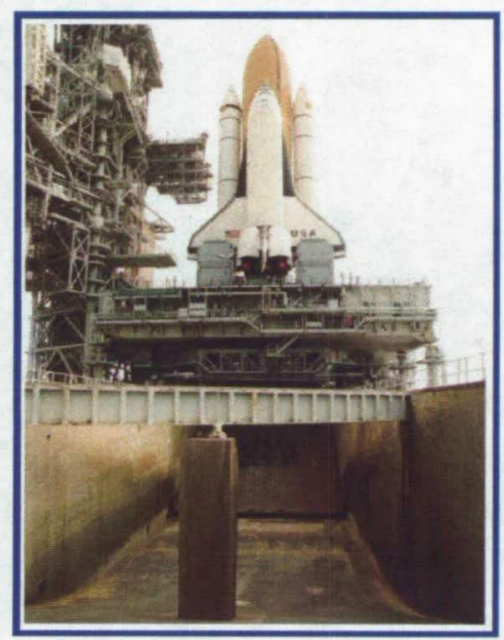

The Shuttle and the flame trench

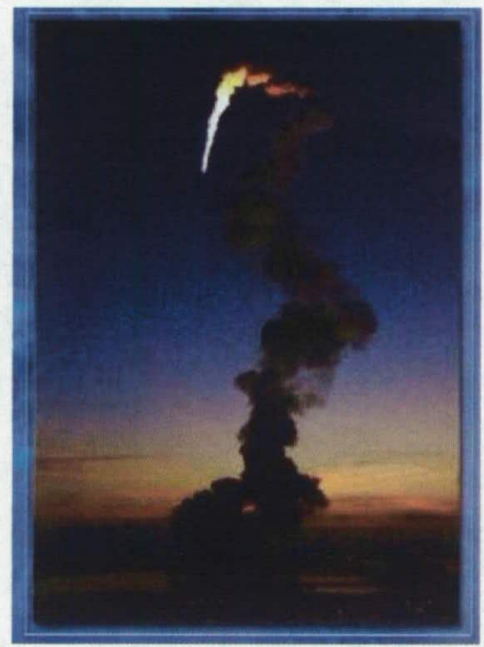

Columbia: corrosion weakened wing may have been vulnerable to impact of debris

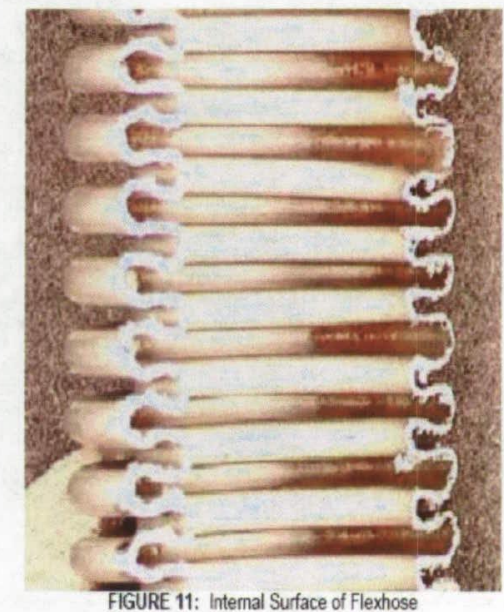

Inside the flexhoses, which are used throughout the vehicle in the Main Propulsion, Environmental Control and Life Support, Orbiter Maneuvering, etc. 


\section{Smart Materials Concept}

The use of "smart materials" for corrosion sensing relies on a material undergoing a transformation through its interaction with the corrosive environment.

Such transformations can potentially be used for indicating and detecting corrosion damage. Ideally, the sensing function could be integrated with additional actuation and control functions, designed to control corrosion damage.

Examples of corrosion sensing coatings:

- Paint systems with color-changing compounds that respond to the $\mathrm{pH}$ changes that result from corrosion processes.

- Changes of coating compounds from non-fluorescent to fluorescent states.

- Release of color dyes on coating damage from incorporated dye-filled microcapsules.

The best coatings for corrosion protection provide not only barriers to the environment, but also a control release of a corrosion inhibitor, as demanded by coating damage and the presence of a corrosive environment. Past examples include coatings containing metallic zinc, such as the zinc-rich paint systems, and chromate. 


\section{Introduction}

\section{Smart Coatings for Corrosion Application}

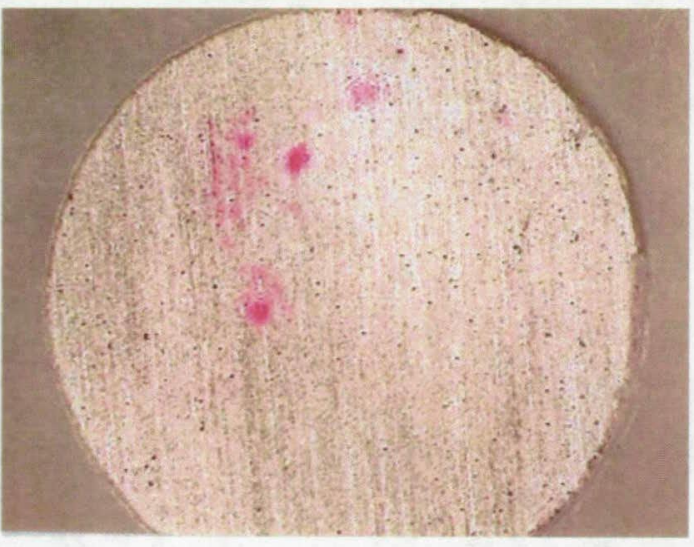

Sample coated with acrylic + phenophthalein (critical $\mathrm{PH}=10$ ) following exposure to $1 \mathrm{M}$ $\mathrm{NaCl}$ for 8 days.

http://www.mse.eng.ohio-

state.edu/fac_staff/faculty/frankel/frankel.html

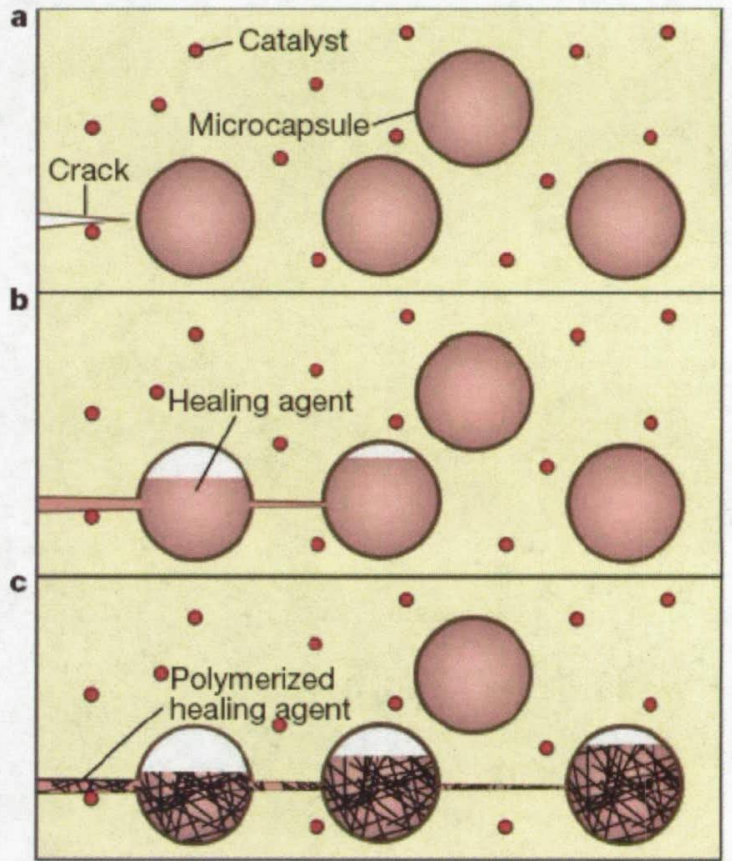

S. R. White, Nature, 409, 794-797, 2001 


\section{Objective of Research}

- Develop a paint system that can detect and repair corrosion at a very early stage without human intervention

- This system should be easily adapted for delivery of new corrosion inhibitor compounds. 


\section{Technique Approach}

Microcapsule containing $\mathrm{pH}$ indicator (inhibitor, self healing agents)

The shell of the microcapsule breaks down under basic $\mathrm{pH}$ conditions through the ester hydrolysis reaction

$\mathrm{pH}$ indictor changes color and is released from the microcapsule under basic conditions

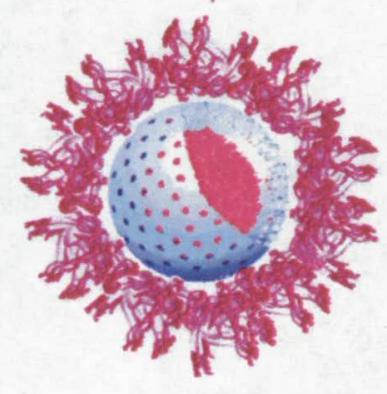

paint system including microcapsules for corrosion detection/inhibition, at localized corrosion site: Microcapsule releases its contents, $\mathrm{pH}$ indicators show color change, corrosion inhibitors prevent further corrosion. 


\section{Electrochemical Nature of Corrosion}

- Overall Reaction

$$
2 \mathrm{H}_{2} \mathrm{O}+\mathrm{O}_{2}+2 \mathrm{Fe} \rightarrow 2 \mathrm{Fe}^{2+}+4 \mathrm{OH}^{-}
$$

- Anodic Reaction

$$
\mathrm{Fe} \rightarrow \mathrm{Fe}^{2+}+2 e^{-}
$$

- Cathodic

$$
2 \mathrm{H}_{2} \mathrm{O}+\mathrm{O}_{2}+4 e^{-} \rightarrow 4 \mathrm{OH}^{-}
$$
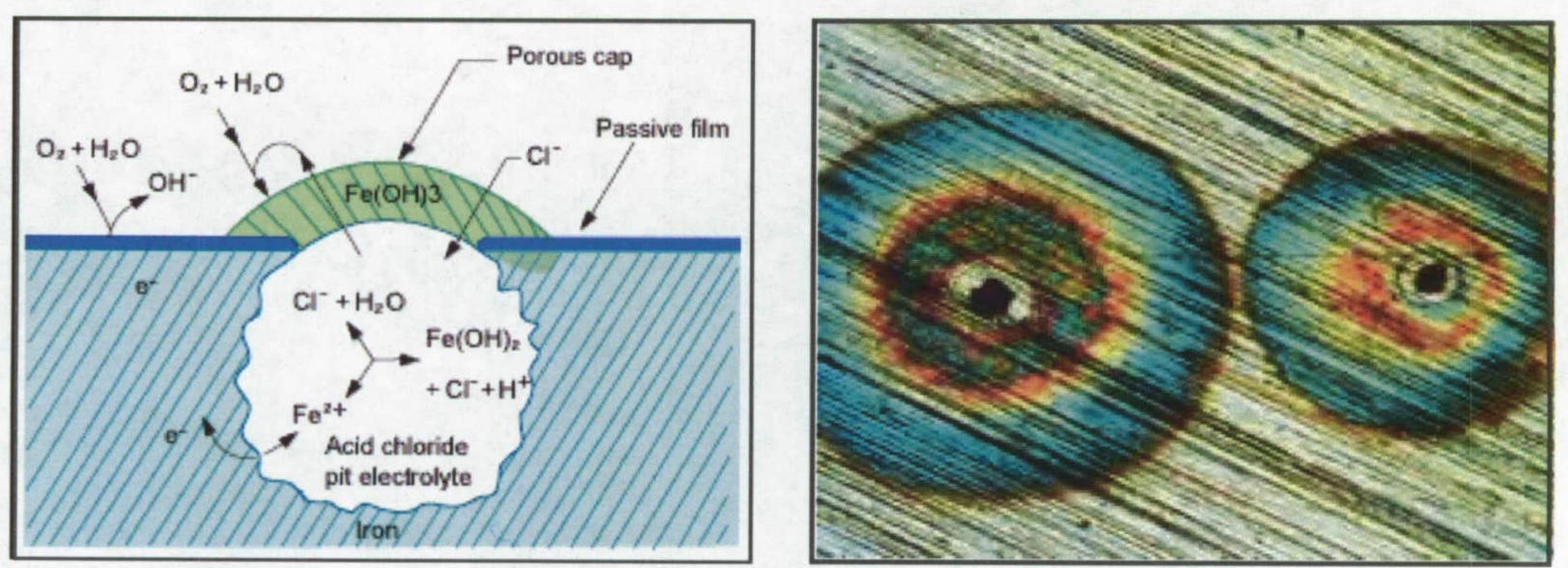

basic $\mathrm{pH}$ conditions at localized corrosion cathodic sites 


\section{Function of Smart Coating}

Microcapsule containing $\mathrm{pH}$ indicator (inhibitor, self healing agents)

The shell of the microcapsule breaks down under basic $\mathrm{pH}$ conditions through the ester hydrolysis reaction

$\mathrm{pH}$ indictor changes color and is released from the microcapsule under basic conditions

paint system including microcapsules for corrosion detection/inhibition, at localized corrosion site: Microcapsule releases its contents, $\mathrm{pH}$ indicators show color change, corrosion inhibitors prevent further corrosion. 


\section{Experimental Approach}

- Synthesis of Microcapsules

- Test Microcapsules for $\mathrm{pH}$ response

- Refine encapsulation process for improved $\mathrm{pH}$ response

- Develop paint system with microcapsules (10-15 wt\%)

- Paint system is currently being tested 


\section{Microcapsule Synthesis}

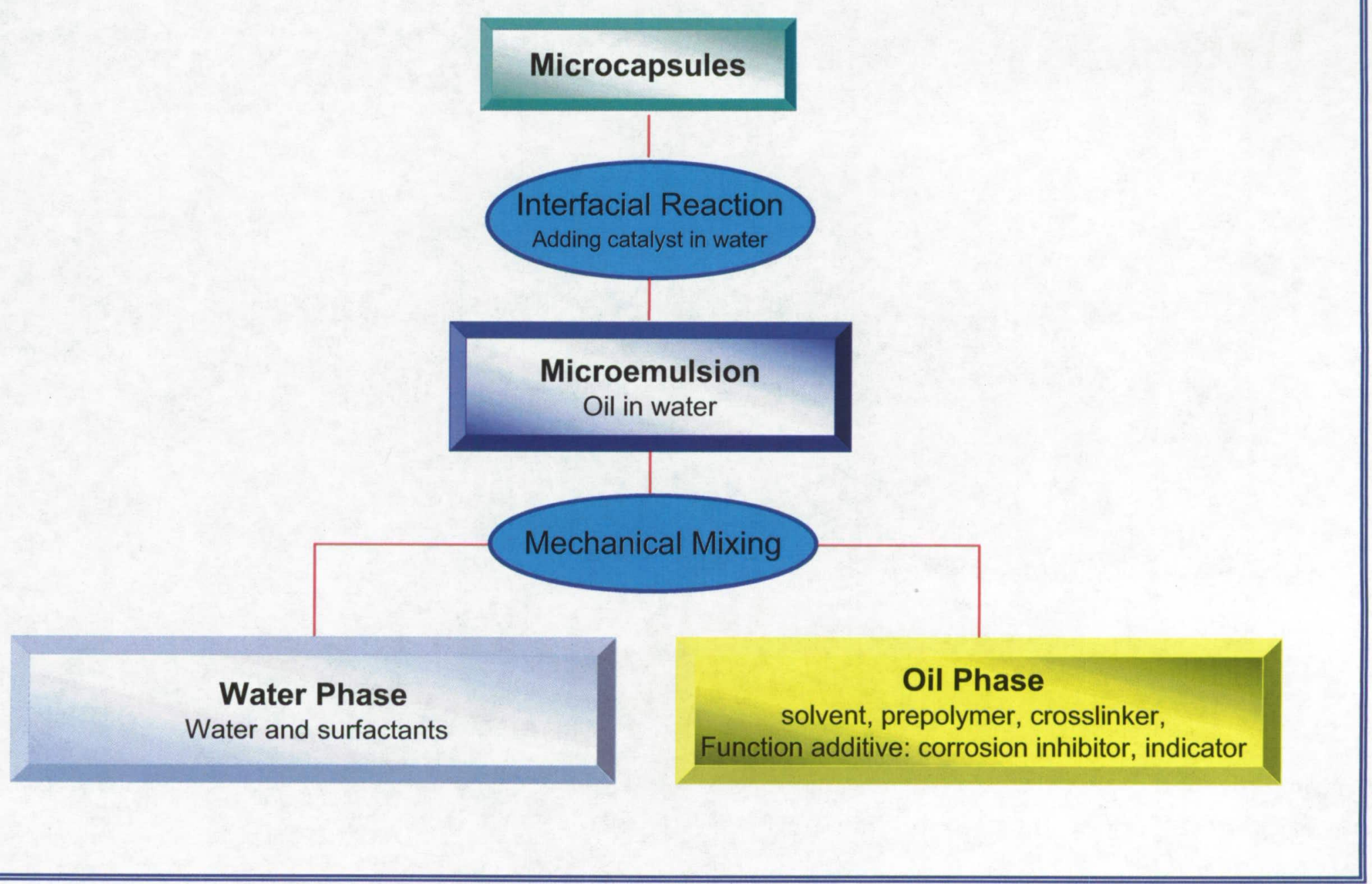




\section{Microemulsion Formation}
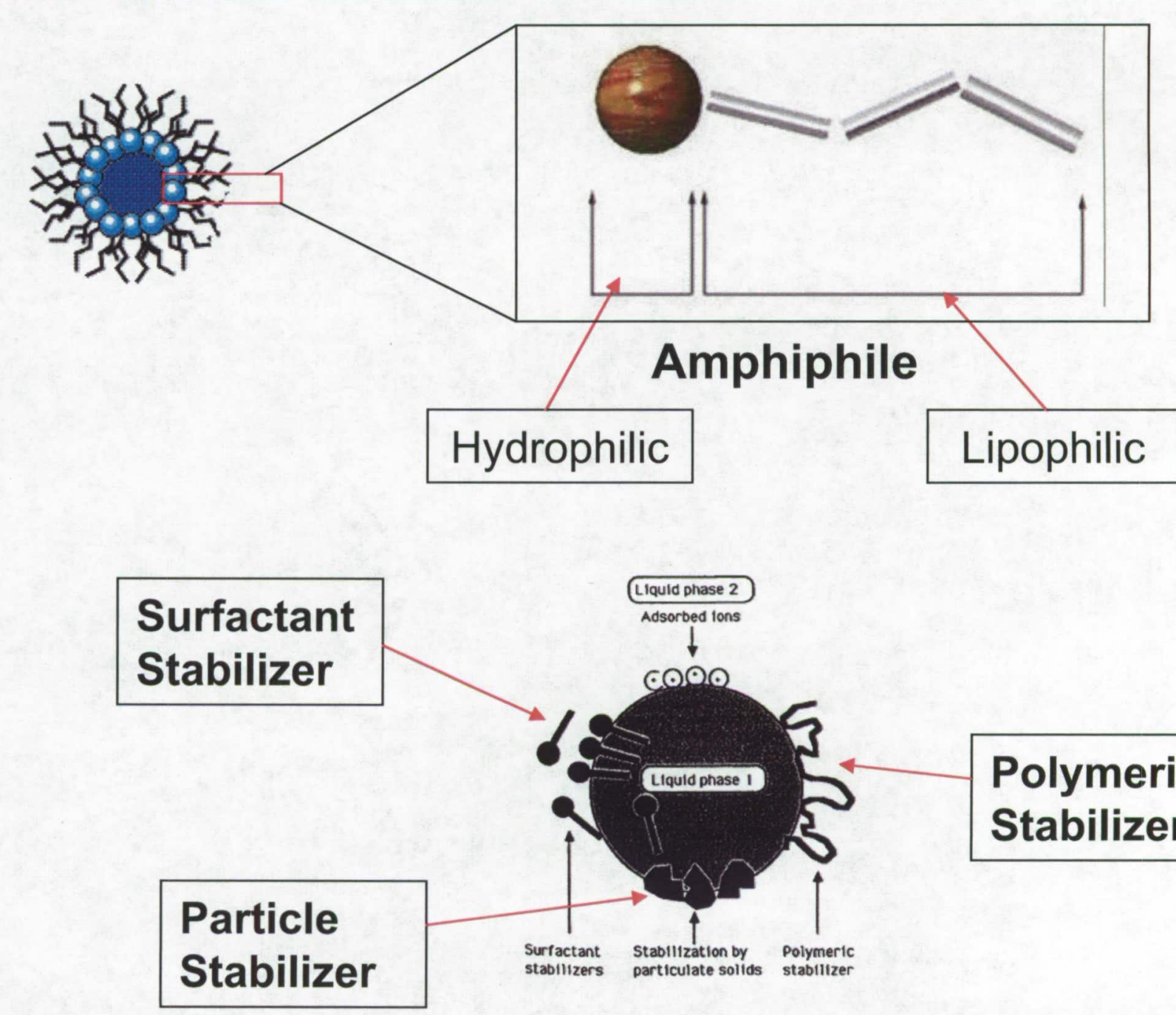

Polymeric Stabilizer 


\section{Experimental}

\section{Interfacial Polymerization}

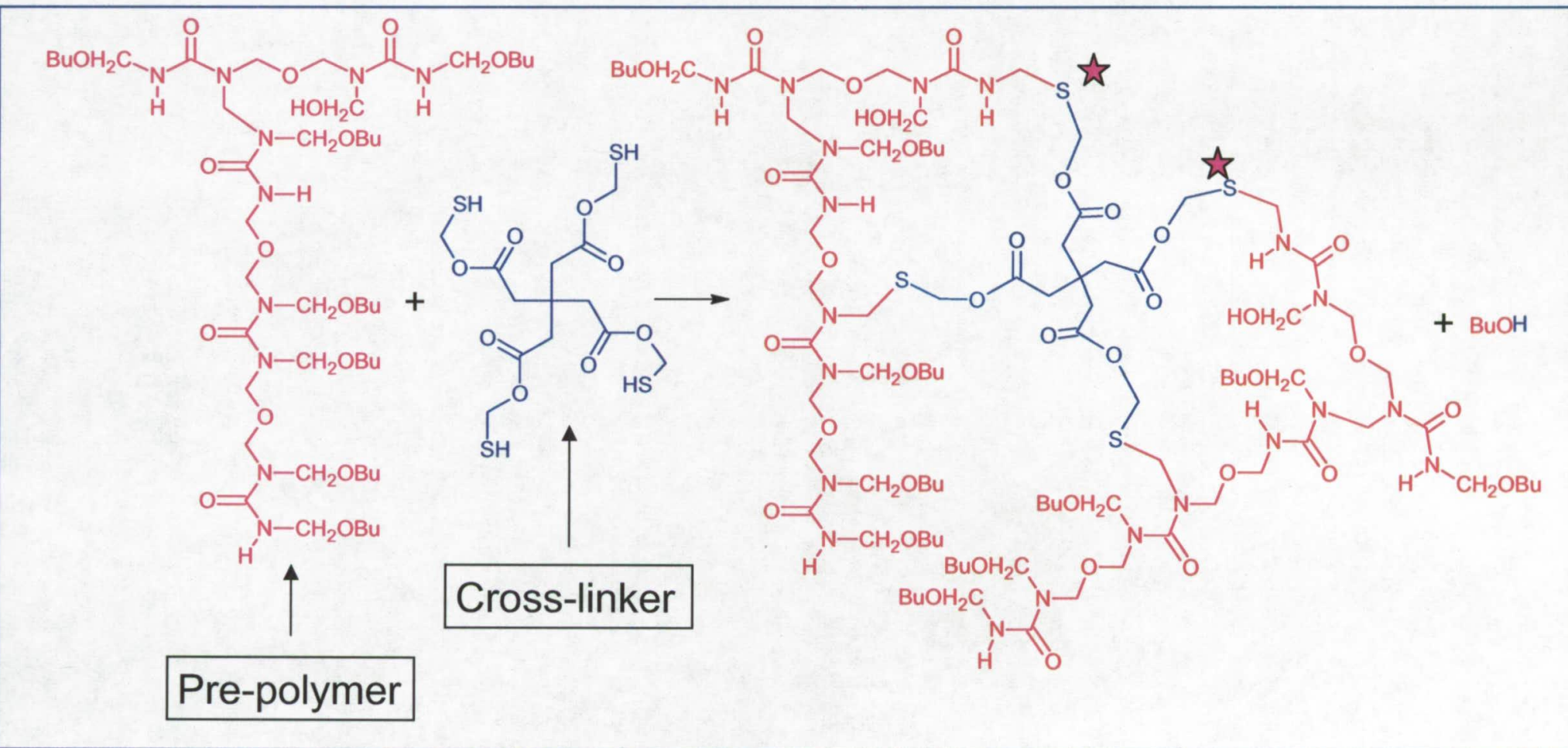

NASA

- A polymerization reaction that occurs at the interface of two immiscible liquids

- The bonds denoted by $\hbar$ are susceptible to break under basic $\mathrm{pH}$ conditions. 


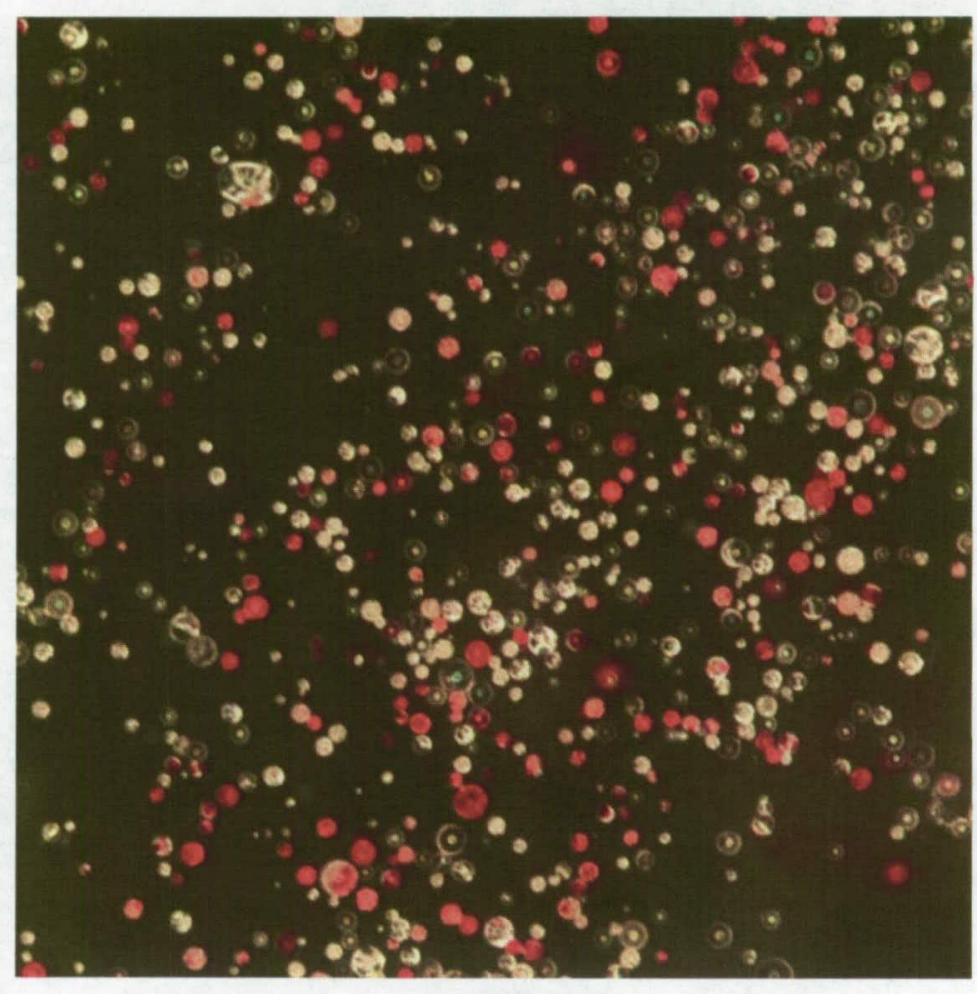

Color change due to Microcapsules in solution responding to basic $\mathrm{pH}$ conditions 


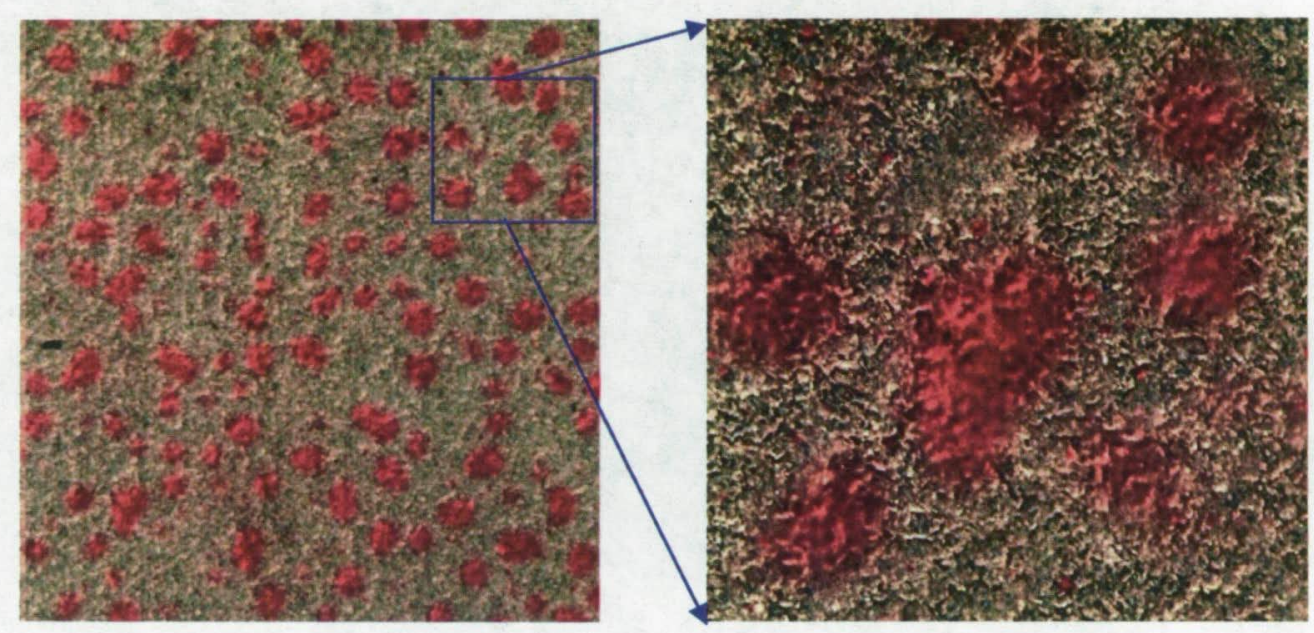

Microcapsules in paint responding to basic $\mathrm{pH}$ conditions

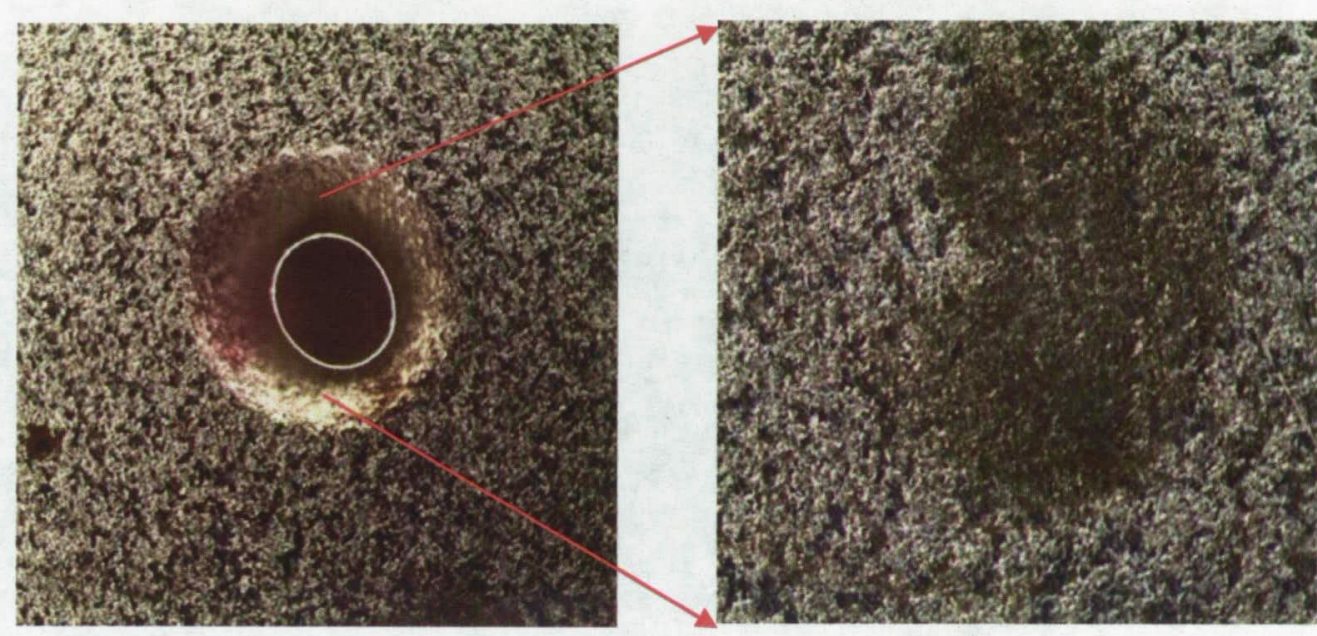

Microcapsules indicating presence of localized corrosion 


\section{Benefits of Microcapsule Design}

- Early detection is important for economic and safety reasons

- Made possible by the small size of capsule and large concentration of $\mathrm{pH}$ indicator

- Versatility of the microcapsule design

- Allows for different core components to be substituted to increase functionality.

- Can be incorporated into different dispersion systems 


\section{Future Possibilities}

\section{Core Component Additions/Changes}

- Corrosion inhibitor - Increases corrosion resistance of the system

- Fluorescent $\mathrm{pH}$ indicator - Easy to detect, even in very small amounts

- Film forming - Repairs mechanical abrasions or scratches by pre-polymer core additive 


\section{Acknowledgements}

- NRC (National Research Council)

- NASA-SOMD and CDDF Funding

- NASA

Eduardo Lopez del Castillo, Paul Hintze, Peter Marciniak, Patrick Faughnan, Nancy Zeiling

- Univ. of Central Florida Erik Brinley

- ASRC Aerospace

Jerry Curran, Frank Gryn, Mark Kolody, Ray

Anderson 